\title{
Asymmetric Stabilizing Impact of International Reserves
}

\author{
Kyungkeun Kim ${ }^{\mathrm{a}}$ and Dongwon Lee $\mathrm{b}^{\mathrm{b}, *}$ \\ ${ }^{a}$ The Bank of Korea, 39 Namdaemun-ro, Jung-gu, Seoul, 04531, Republic of Korea \\ ${ }^{\mathrm{b}}$ Department of Economics, University of California, Riverside, CA 92521, United States
}

This version: May 23, 2017

\begin{abstract}
This paper proposes a panel fixed-effect threshold model to study how different levels of international reserves contribute to stabilizing the exchange rates in emerging market economies. Our model identifies a reserve-to-debt threshold ratio after which the marginal stabilizing effect of reserves begins to fall during tranquil times. Such diminishing returns, however, do not appear to exist even at the excessive level of reserves during the recent global financial crisis. These results call for deeper international macro cooperation through reserve pooling or swap arrangements to enhance efficiency of reserve management.
\end{abstract}

JEL classification: F31, F33

Keywords: Diminishing returns; Exchange rate volatility; Global financial crisis; International reserves

\footnotetext{
* Corresponding author. Tel.: +1-951-827-1505; fax: +1-951-827-5685.

E-mail addresses: kkkim@bok.or.kr (K. Kim),dwlee@ucr.edu (D. Lee).
} 


\section{Introduction}

The most widely used benchmark for an international reserve adequacy ratio suggests that countries hold liquid reserves equal to a full coverage of foreign liabilities maturing within a year (Greenspan-Guidotti rule). However, the amount of reserves in emerging market economies (EMEs) has far deviated from this benchmark rule, particularly in East Asia, after the financial crises of the late 1990s. Two popular arguments for the excess reserve hoarding are a precautionary motive to hedge against future sudden capital reversals, and a mercantilist motive to keep export competitiveness (Aizenman and Lee, 2007). Both motives are intimately linked to exchange rate (ER) management, which motivates our focus on the reserve adequacy ratio and its signaling effect on the nominal ER volatility.

Larger stockpiles of reserves may signify that a country has more capacity for foreign exchange intervention. Also, countries with more reserves relative to short-term debt have generally better weathered the 2008-09 financial crisis (Bussière et al., 2015). Nevertheless, the self-insurance through reserve buildup can involve considerable opportunity costs when there is a wide spread between the rate of return on domestic credit and the risk free rate. ${ }^{1}$ In addition, a non-linear reserve effect on the real exchange rate volatility may raise the efficiency concern of amassing massive reserves (see Hviding et al., 2004).

This paper proposes a panel fixed-effect threshold model to explore the marginal ER stabilizing effect (which we call marginal returns) of reserve accumulation in EMEs, and study the following questions that have not been previously addressed in the literature: i) Is there a particular reserve adequacy ratio after which diminishing returns kick in? ii) Did this point of decreasing returns change during the recent global financial crisis?

\footnotetext{
${ }^{1}$ Rodrik (2006) estimates the cost of excess reserves in developing countries to be around 1\% of their GDP in 2004.
} 


\section{Threshold model specification}

We develop a threshold regression model by adding international reserves and financial crisis to the standard determinants of nominal ER volatility. ${ }^{2}$ The model takes the following form:

$$
\begin{aligned}
\text { vol_NEER } R_{i t}= & \alpha_{1} R A_{i t-1}+\alpha_{2} R A_{i t-1} \times I_{(R / D>\mathrm{p})}+\alpha_{3} R A_{i t-1} \times \text { Crisis } \\
& +\alpha_{4} R A_{i t-1} \times I_{(R / D>\mathrm{p})} \times \text { Crisis }+\beta \text { Crisis }+\boldsymbol{X}_{i t-1} \boldsymbol{\gamma}+\delta_{i}+\varepsilon_{i t}
\end{aligned}
$$

The volatility of the nominal effective exchange rate (NEER) for country $i$ and year $t$, vol_NEER $R_{i t}$, is measured by the standard deviation of monthly log differences $\left(=s t d . \operatorname{dev} \cdot\left[\ln \left(N E E R_{i t, m}\right)-\ln \left(N E E R_{i t, m-1}\right)\right], m=2, \ldots, 12\right)$. The variable of interest, $R A_{i t-1}$, is the reserve adequacy defined as a $\log$ ratio of international reserves $(R)$ to short-term external debt $(D)$ maturing within one year. The indicator function $I_{(R / D>\mathrm{p})}$ takes value of one if the ratio $R_{i t-1} / D_{i t-1}$ is bigger than the designated percentile $\mathrm{p}$. The dummy variable Crisis accounts for the 2008-09 global financial crisis. The vector $\boldsymbol{X}_{i t-1}$ contains real GDP growth (Growth), the volatility of money growth (vol_M2) constructed in the same way as the NEER volatility, the log ratio of total trade to GDP (Trade), broad money M2 to GDP to proxy for local financial development (FinDev), and total external assets plus liabilities to GDP to capture financial openness (FinOpen). The terms $\delta_{i}$ and $\varepsilon_{i t}$ are, respectively, a country-fixed effect and i.i.d. disturbance. All regressors except for dummy variables are lagged by one period to help reduce a potential endogeneity bias associated with reverse causality.

\footnotetext{
${ }^{2}$ See Bayoumi and Eichengreen (1998), Cady and Gonzalez-Garcia (2007), and Devereux and Lane (2003) for modeling the nominal exchange rate volatility. International reserves and their asymmetric stabilizing impacts were not examined in these studies.
} 
The full sample covers 31 countries ( 9 advanced, 20 emerging and 2 developing) over the period 2001-2013. ${ }^{3}$ See Table A1 in Appendix for data sources.

In Eq. (1), $\alpha_{1}$ reflects the ER volatility effect of reserves-to-debt ratio if it is smaller than or equal to the selected percentile in tranquil times, while $\left(\alpha_{1}+\alpha_{2}\right)$ represents the effect of that ratio if it is bigger than the chosen percentile. During the crisis, the effect of stabilizing the ER volatility is captured by $\left(\alpha_{1}+\alpha_{3}\right)$ if $R_{i t-1} / D_{i t-1} \leq \mathrm{p}$, and by $\left(\left(\alpha_{1}+\alpha_{3}\right)+\left(\alpha_{2}+\alpha_{4}\right)\right)$ if $R_{i t-1} / D_{i t-1}>\mathrm{p}$

Cross-sectional dependence is likely to be present in our specification because of the ER volatility effect of common global shocks such as world business cycles and cross-country spillovers across trading partners. Indeed, the null of cross-sectional independence is strongly rejected on the residuals of our baseline model (1) at the $1 \%$ significance level according to the Pesaran (2004)'s test (results available upon request). In order to correct for spatial correlation in addition to autocorrelation and heteroscedasticity, we use Driscoll and Kraay (1998) standard errors in our estimations. We also report F-statistics for a Wald test since testing the null hypothesis that reserves have no effect on the ER volatility requires a joint significance test for $\alpha$ 's from model (1).

\section{Empirical results}

As a first step, we examine a potential non-linear effect of reserves on the ER volatility in a general setting. To do so, we replace the indicator function $I_{(\cdot)}$ in Eq. (1) by $R A_{i t-1}$ to introduce

\footnotetext{
${ }^{3}$ Advanced countries: Australia, Canada, Denmark, Japan, Norway, Sweden, Switzerland, United Kingdom, and United States; Emerging countries: Argentina, Brazil, Bulgaria, Chile, China, Colombia, Czech Republic, Egypt, Hungary, Indonesia, Korea, Malaysia, Mexico, Pakistan, Philippines, Poland, Russia, South Africa, Turkey, and Venezuela; Developing countries: Costa Rica and Dominican Republic.
} 
quadratic terms. As seen from Table 1 columns (1), (3), (4) and (6), a negative and statistically significant $\hat{\alpha}_{1}$ verifies an ER stabilizing role of reserve accumulation during normal times, and a positive $\hat{\alpha}_{2}$ indicates convexity of the stabilizing effect. While amassing reserves initially helps reduce the ER volatility in the next period, the size of this buffering effect becomes smaller as a reserves-to-debt ratio rises, suggesting the presence of diminishing returns to reserve accumulation.

Moreover, the results in columns (4)-(6) show that, during the period of the recent global financial crash, reserves' mitigating effect becomes weaker $\left(\left|\hat{\alpha}_{1}+\hat{\alpha}_{3}\right|<\left|\hat{\alpha}_{1}\right|\right)$, but at the same time decreasing returns to reserve hoarding are not as strong as they are in good times $\left(\hat{\alpha}_{2}+\right.$ $\hat{\alpha}_{4}<\hat{\alpha}_{2}$ ). These results are particularly prominent in EMEs, reflecting that a relationship between the ER volatility and reserves may depend on the level of reserve adequacy, whose difference is huge between advanced and emerging market countries (see the last row in Table 1). In fact, the reserve adequacy shows no significant signaling effect in advanced countries during our sample period and thus our focus in the subsequent analysis will center on EMEs.

Regarding other control variables, the ER volatility seems positively related to financial stress and variations in the money growth, and negatively to the output growth. In addition, higher domestic financial development with more liquidity tends to increase, rather than decrease, the currency volatility in advanced economies, but not in EMEs. The effect of trade and financial openness is not statistically different from zero.

The next step is to introduce a threshold analysis by letting the stabilizing effect vary at the different levels of reserves. From negative $\hat{\alpha}_{1}$ in Table 2, we find that reserves generally act as a buffer for ER shocks during tranquil periods. Note that at each specified reserve-to-debt threshold ratio, $\hat{\alpha}_{2}$ is supposed to be statistically significant and positive if (marginal) returns to 
reserve buildup decline. As shown by positive $\hat{\alpha}_{2}$ in columns (2)-(5), the diminishing returns kick in once the reserve adequacy ratio exceeds a threshold of the $50^{\text {th }}$ percentile during normal times, which is a level roughly 2.33 times higher than the Greenspan-Guidotti benchmark. ${ }^{4}$

We investigate next whether reserves exhibit a similar non-linear effect during the recent global financial crisis. From positive $\hat{\alpha}_{3}$ in Table 2, we see that exposure to severe global financial turbulence that brings about large swings in the ER and increased vulnerability to external shocks generally weakens the smoothing effect of reserves. We also find that decreasing returns with respect to the ER stabilization may come into play once the reserve adequacy ratio reaches the $30^{\text {th }}$ percentile (inferred from $\left(\hat{\alpha}_{2}+\hat{\alpha}_{4}\right)>0$ in column (1)). However, such diminishing returns do not continue to exist at the higher level of reserves. Interestingly enough, large stocks of reserves above the $70^{\text {th }}$ percentile (equivalent to $R / D=3.13$ ) tend to make the magnitude of decreasing returns much smaller during stress times, and can even lead to increasing returns as seen in columns (3)-(5). ${ }^{5}$ In other words, during the crisis, the reserve buildup does help buffer the EX shocks (albeit less effective than good times) and its marginal mitigating effect does not decline even at the excessive level of reserves.

In order to check the robustness of the main results presented in Table 2, we carry out additional tests (results available upon request). Firstly, we introduce a lagged dependent variable to Eq. (1) to control for possible persistence in the ER volatility. The Arellano-Bond (1991) difference and system GMM estimations find that large reserve-to-debt ratios above the $55^{\text {th }}(R / D=2.42)$ percentile in EMEs are subject to decreasing returns to reserve storing in good times, but increasing returns when the reserve adequacy ratio exceeds the $70^{\text {th }}$ percentile in

\footnotetext{
${ }^{4}$ We find no evidence of decreasing returns at the $40^{\text {th }}$ and $45^{\text {th }}$ percentiles during tranquil periods.

${ }^{5}$ Additional regressions show that the threshold coefficient $\alpha_{4}$ is not statistically significant at the $60^{\text {th }}$ and $65^{\text {th }}$ percentiles.
} 
bad times. Secondly, we check whether the main results hold with the full sample. The results replicate those obtained using the EMEs with a diminishing returns threshold at the $65^{\text {th }}$ percentile $(R / D=2.39)$ in normal times, but little or no decreasing returns above the $80^{\text {th }}$ percentile $(R / D=3.37)$ in times of global peril. Overall, the results are broadly consistent with those in Table 2.

\section{Conclusion}

This paper presents that the vast stockpile of international reserves certainly helps mitigate the exchange rate fluctuations. However, it exhibits the asymmetric stabilizing impact depending on the state of the economy. Amassing excess reserves is costly during normal times due to the apparent presence of decreasing marginal returns in buffering the exchange rate volatility. Conversely, diminishing returns to massive reserves barely exist when global financial stress arises. These results call for amending benchmark optimal reserves to reflect diminishing returns and their state-dependency. Additionally, the results also suggest the extension of deeper international macro cooperation through reserve pooling or swap arrangements to enhance efficiency of reserve management in emerging market economies. 
Table 1

Exchange rate volatility and reserve-to-debt ratio: nonlinear relationship.

\begin{tabular}{|c|c|c|c|c|c|c|}
\hline & Full sample & Advanced & Emerging & Full sample & Advanced & Emerging \\
\hline & $(1)$ & $(2)$ & (3) & (4) & (5) & (6) \\
\hline \multirow[t]{2}{*}{$R A$} & $-0.057 * * *$ & 0.029 & $-0.067 * * *$ & $-0.059 * * *$ & 0.037 & $-0.074 * * *$ \\
\hline & $(0.011)$ & $(0.030)$ & $(0.011)$ & $(0.010)$ & $(0.028)$ & $(0.011)$ \\
\hline \multirow[t]{2}{*}{$R A^{2}$} & $0.015^{* * *}$ & 0.005 & $0.018 * * *$ & $0.016^{* * *}$ & -0.021 & $0.020 * * *$ \\
\hline & $(0.003)$ & $(0.052)$ & $(0.003)$ & $(0.002)$ & $(0.049)$ & $(0.003)$ \\
\hline \multirow[t]{2}{*}{$R A \times$ Crisis } & & & & $0.012 * * *$ & -0.029 & $0.053 * * *$ \\
\hline & & & & $(0.003)$ & $(0.020)$ & $(0.013)$ \\
\hline \multirow[t]{2}{*}{$R A^{2} \times$ Crisis } & & & & $-0.004 * *$ & 0.051 & $-0.017 * * *$ \\
\hline & & & & $(0.002)$ & $(0.032)$ & $(0.004)$ \\
\hline \multirow[t]{2}{*}{ Crisis } & $0.008 * * *$ & $0.010 * * *$ & $0.009 * * *$ & 0.002 & $0.012 * * *$ & $-0.028 * * *$ \\
\hline & $(0.003)$ & $(0.001)$ & $(0.003)$ & $(0.002)$ & $(0.002)$ & $(0.010)$ \\
\hline \multirow[t]{2}{*}{ Growth } & $-0.001 * *$ & -0.0002 & $-0.001 * *$ & $-0.001 * *$ & -0.0001 & $-0.001 * *$ \\
\hline & $(0.0003)$ & $(0.0002)$ & $(0.0003)$ & $(0.0003)$ & $(0.0002)$ & $(0.0003)$ \\
\hline \multirow[t]{2}{*}{ vol_M2 } & $0.750 * *$ & -0.097 & $0.797 * *$ & $0.752 * *$ & -0.115 & $0.783 * *$ \\
\hline & $(0.352)$ & $(0.097)$ & $(0.344)$ & $(0.352)$ & $(0.092)$ & $(0.354)$ \\
\hline \multirow[t]{2}{*}{ Trade } & -0.011 & 0.005 & $-0.015^{*}$ & -0.012 & 0.004 & -0.014 \\
\hline & $(0.008)$ & $(0.011)$ & $(0.008)$ & $(0.008)$ & $(0.011)$ & $(0.008)$ \\
\hline \multirow[t]{2}{*}{ FinDev } & -0.004 & $0.019 * *$ & -0.016 & -0.009 & $0.019 * *$ & -0.017 \\
\hline & $(0.013)$ & $(0.007)$ & $(0.017)$ & $(0.015)$ & $(0.006)$ & $(0.019)$ \\
\hline \multirow[t]{2}{*}{ FinOpen } & 0.000 & 0.003 & -0.002 & 0.002 & 0.002 & -0.002 \\
\hline & $(0.008)$ & $(0.005)$ & $(0.009)$ & $(0.008)$ & $(0.006)$ & $(0.009)$ \\
\hline$F$-statistics & $14.75^{* * *}$ & 1.87 & $18.40 * * *$ & $33.95 * * *$ & $40.00 * * *$ & $34.39 * * *$ \\
\hline$R^{2}$ within & 0.334 & 0.458 & 0.374 & 0.339 & 0.468 & 0.384 \\
\hline No. countries & 31 & 9 & 22 & 31 & 9 & 22 \\
\hline Observations & 339 & 87 & 252 & 339 & 87 & 252 \\
\hline Median $R / D$ & 1.711 & 0.140 & 2.326 & 1.711 & 0.140 & 2.326 \\
\hline
\end{tabular}

Note: The dependent variable is the volatility of the nominal effective exchange rate. $R A$ is the reserve adequacy defined as a $\log$ ratio of international reserves $(R)$ to short-term debt $(D)$. Crisis controls for the 2008-09 global financial crisis. Growth corresponds to the real GDP growth. vol_M2 indicates the volatility of the money growth. Trade represents total trade as a share of GDP. FinDev denotes financial development. FinOpen stands for financial openness. All specifications include country fixed effects. Driscoll-Kraay standard errors are reported in parentheses. ${ }^{* * *}, * *, *$ indicate $1 \%, 5 \%$ and $10 \%$ levels of significance. 
Table 2

Exchange rate volatility and reserve-to-debt ratio: threshold analysis.

\begin{tabular}{|c|c|c|c|c|c|}
\hline & (1) & (2) & (3) & (4) & $(5)$ \\
\hline & $\mathrm{p} 30=1.614$ & $\mathrm{p} 50=2.326$ & $\mathrm{p} 70=3.127$ & p90 $=6.185$ & $\mathrm{p} 95=8.314$ \\
\hline$R A$ & $-0.010^{* *}(0.005)$ & $-0.026 * * *(0.004)$ & $-0.026 * * *(0.005)$ & $-0.026 * * *(0.005)$ & $-0.021 * * *(0.004)$ \\
\hline$R A \times I_{(R / D>\mathrm{p} 30)}$ & $-0.004(0.003)$ & & & & \\
\hline$R A \times I_{(R / D>\mathrm{p} 50)}$ & & $0.006 * * *(0.001)$ & & & \\
\hline$R A \times I_{(R / D>\mathrm{p} 70)}$ & & & $0.007 * * *(0.002)$ & & \\
\hline$R A \times I_{(R / D>\mathrm{p} 90)}$ & & & & $0.009 * * *(0.002)$ & \\
\hline$R A \times I_{(R / D>\mathrm{p} 95)}$ & & & & & $0.006 * * *(0.001)$ \\
\hline$R A \times$ Crisis & $-0.019(0.012)$ & $0.011 * *(0.005)$ & $0.023 * * *(0.006)$ & $0.013 * * *(0.004)$ & $0.009 * * *(0.003)$ \\
\hline$R A \times I_{(R / D>\mathrm{p} 30)} \times$ Crisis & $0.016 * *(0.007)$ & & & & \\
\hline$R A \times I_{(R / D>\mathrm{p} 50)} \times$ Crisis & & $-0.004(0.003)$ & & & \\
\hline$R A \times I_{(R / D>\mathrm{p} 70)} \times$ Crisis & & & $-0.011 * * *(0.004)$ & & \\
\hline$R A \times I_{(R / D>\mathrm{p} 90)} \times$ Crisis & & & & $-0.008 * * *(0.002)$ & \\
\hline$R A \times I_{(R / D>\mathrm{p} 95)} \times$ Crisis & & & & & $-0.007 * * *(0.002)$ \\
\hline Crisis & $0.017(0.011)$ & $-0.002(0.005)$ & $-0.014 * *(0.005)$ & $-0.005(0.006)$ & $-0.002(0.005)$ \\
\hline Growth & $-0.001 * *(0.0003)$ & $-0.001 * *(0.0003)$ & $-0.001 * *(0.0003)$ & $-0.001 * *(0.0003)$ & $-0.001 * *(0.0003)$ \\
\hline vol_M2 & $0.867 * *(0.373)$ & $0.849 * *(0.372)$ & $0.850 * *(0.367)$ & $0.822 * *(0.365)$ & $0.847 * *(0.370)$ \\
\hline Trade & $-0.007(0.007)$ & $-0.006(0.006)$ & $-0.008(0.007)$ & $-0.010(0.007)$ & $-0.008(0.007)$ \\
\hline FinDev & $-0.001(0.018)$ & $0.003(0.016)$ & $-0.008(0.015)$ & $-0.009(0.018)$ & $-0.002(0.018)$ \\
\hline FinOpen & $-0.004(0.011)$ & $-0.003(0.010)$ & $-0.001(0.011)$ & $-0.004(0.010)$ & $-0.005(0.010)$ \\
\hline$F$-statistics & $18.08 * * *$ & $11.62 * * *$ & $9.99 * * *$ & $11.10 * * *$ & $17.65 * * *$ \\
\hline$R^{2}$ within & 0.329 & 0.334 & 0.341 & 0.351 & 0.337 \\
\hline No. countries/observations & $22 / 252$ & $22 / 252$ & $22 / 252$ & $22 / 252$ & $22 / 252$ \\
\hline
\end{tabular}

See note to Table 1 . The sample here excludes advanced countries. 


\section{Appendix}

\section{Table A1}

Data sources.

\begin{tabular}{ll}
\hline Variable & Source \\
\hline$N E E R$ & BIS and IMF IFS \\
$R$ & World Bank WDI \\
$D$ & World Bank WDI and Joint BIS-IMF-OECD-WB External Debt Hub \\
Growth & World Bank WDI \\
$M 2^{\text {a }}$ & IMF IFS and St. Louis Fed's FRED database \\
Trade & World Bank WDI \\
FinOpen & Lane and Milesi-Ferretti (2007) \\
NGDP & World Bank WDI \\
\hline
\end{tabular}

${ }^{\mathrm{a}}$ The data are unavailable for Australia and Philippines and replaced with M3. 


\section{References}

Aizenman, J., Lee, J., 2007. International reserves: Precautionary versus mercantilist views, theory and evidence. Open Econ. Rev. 18, 191-214.

Arellano, M., Bond, S., 1991. Some tests of specification for panel data: Monte Carlo evidence and an application to employment equations. Rev. Econ. Stud. 58, 277-297.

Bayoumi, T., Eichengreen, B., 1998. Exchange rate volatility and intervention: Implications of the theory of optimum currency areas. J. Int. Econ. 45, 191-209.

Bussière, M., Cheng, G., Chinn, M.D., Lisack, N., 2015. For a few dollars more: Reserves and growth in times of crises. J. Int. Money Finance 52, 127-145.

Cady, J., Gonzalez-Garcia, J., 2007. Exchange rate volatility and reserves transparency. IMF Econ. Rev. 54, 741-754.

Devereux, M.B., Lane, P.R., 2003. Understanding bilateral exchange rate volatility. J. Int. Econ. $60,109-132$.

Driscoll, J.C., Kraay, A.C., 1998. Consistent covariance matrix estimation with spatially dependent panel data. Rev. Econ. Stat. 80, 549-60.

Hviding, K., Nowak, M., Ricci, L.A., 2004. Can higher reserves help reduce exchange rate volatility? IMF Working Paper No. 04/189.

Lane, P.R., Milesi-Ferretti, G.M., 2007. The external wealth of nations mark II: revised and extended estimates of foreign assets and liabilities, 1970-2004. J. Int. Econ. 73, 223-50.

Pesaran, M.H., 2004. General diagnostic tests for cross section dependence in panels, CESifo Working Paper 1229.

Rodrik, D., 2006. The social cost of foreign exchange reserves. Int. Econ. J. 20, 253-266. 